\title{
Outcomes of Fixation of Slipped Capital Femoral Epiphysis with Single Cannulated Screw
}

\author{
(D) Tunay Erden ${ }^{1}$, (D) Ali Tufan Pehlivan² \\ ${ }^{1}$ Acıbadem Fulya Hospital, Clinic of Orthopedics and Traumatology, Istanbul, Turkey \\ 2Fatih Sultan Mehmet Training and Research Hospital, Clinic of Orthopedics and Traumatology, Istanbul, Turkey
}

\section{Abstract}

Objective: Slipped capital femoral epiphysis (SCFE) or epiphysiolysis is a common pathology that requires urgent surgical intervention. This study aims at evaluating clinical and radiological mid-term results of our patients diagnosed with SCFE and fixed with a single cannulated screw.

Methods: We examined 13 hips of 12 patients treated with SCFE and evaluated mid-term results in our study.

Results: All of our patients were male with a mean age of 11.8 years (range 7-15). The mean slip angle was calculated as 43.20 degrees (range 26-70), and the average length of follow-up was 19 months (range 14-29 months). The average body mass index was 26.8 (range 24.429.7), and 11 patients were overweight (91.7\%). Concerning ambulation, 7 patients had stable SCFE (58.3\%), and 5 had unstable SCFE (41.6\%). According to the Southwick classification, the average sliding angle of the patients was 43.2 degrees (range 26-70). Fixation was performed with a single cannulated screw for all patients. No patients were applied screws to the opposite hip for prophylactic purposes. Loss of reduction was not observed in any of our patients who followed up on average for 19 months (range 14 to 29). In radiological follow-ups, SCFE was not observed in the opposite hip of any patient. The postoperative range of motion was normal in all patients. Shortness and limping were not observed in any case.

Conclusion: We suggest that in SCFE cases requiring urgent surgery, the mild reduction can be considered, and subsequent osteosynthesis with a single screw is a sufficient treatment.

Keywords: Slipped capital femoral epiphysis, hip disorders, pediatric, adolescent, hip

\section{INTRODUCTION}

Slipped capital femoral epiphysis (SCFE) or epiphysiolysis is a common disease seen in pediatric patients, where the femoral head growth plate displaced inferiorly and posteriorly according to the length and is most common in the age range of $10-16$ years $(1,2)$. Its incidence is around 3-10/100,000 (3). The boy/girl ratio is about 1.4 and is more common in the black race (4). The etiology and treatment of SCFE remain controversial. They can be caused by various factors such as stress on the growth plate due to obesity, endocrine disorders (hypothyroidism, panhypopituitarism, and renal osteodystrophy), and the period of a rapid growth spurt during adolescence (5).
A characteristic patient presents with an antalgic gait and externally rotated limb with possible shortening, non-specific thigh-, groin-, or referred knee pain, and altered abductor function with exercise-triggered weakness of the lower extremity (5). There are delays in diagnosis in patients whose hip complaints are not at the forefront. In physical examination, decreased hip movements and minimal internal rotation should suggest SCFE in the differential diagnosis. Diagnosis of the disease can be made by hip anterior-posterior (AP) and lateral radiographs. Early diagnosis and appropriate treatment can reduce the morbidity and complications of SCFE, including arthrosis, loss of motion, and pain (6). 
After diagnosis, surgical stabilization is indicated in which the surgical options are determined by the severity of the slip, the presumed duration of the disease (acute or chronic), and the expertise of the treating surgeon. Various treatment options have been proposed, including bone peg epiphysiodesis, pinning in situ closed reduction and pinning, open reduction and physeal osteotomy, open reduction and internal fixation, and Ganz surgical dislocation. However, the surgical procedure involving the placement of one screw across the growth plate is technically straightforward, considered minimally invasive, and continues to be widely used $(3,7)$. Complications such as femoral head avascular necrosis, chondrolysis, nerve injury, implant failure, infection, subtrochanteric fracture, and continued slippage can be seen after surgical treatment $(3,7,8)$.

Our study aimed to evaluate clinical and radiological mid-term results of the sliding femoral head epiphysis after mild reduction with a single screw or fixation in the position where it is located.

\section{METHODS}

The study was conducted following the ethical standards stated in the "Declaration of Helsinki" and was approved by the Local Ethics Committee of Fatih Sultan Mehmet Training and Research Hospital (number: 17073117-050.06). Informed consent was obtained from all patients.

A total of 12 patients were admitted to our emergency department or orthopedics outpatient clinic with complaints of hip, knee, thigh pain, and limping, and diagnosed with SCFE after the physical examination and X-ray graphs were included in the study (Figure 1). Internal fixation was performed on 13 hips of 12 patients, including 6 in its position and 7 after mild reduction with a single cannulated screw. All of the patients were male. Five of our patients were examined as acute and two as chronic sliding. No patient underwent surgery on the prophylactic contralateral hip. The degrees of sliding was determined on the lateral graphy using the Southwick classification (9). According to this classification, those with a sliding below 30 degrees were classified as mild, those with sliding between 30 and 60 degrees were classified as moderate, and those with a sliding higher than 60 degrees were classified as severe (Table 1). SCFE cases were classified as stable and unstable according to the way patients were referred to the emergency department, and the stability was confirmed by intra-operative scopy. Heyman-Herndon classification was used in the clinical examination of our cases (Table 2) (10).

All patients were operated on the traction table under general anesthesia. A mini-incision was entered lateral to the hip, where the

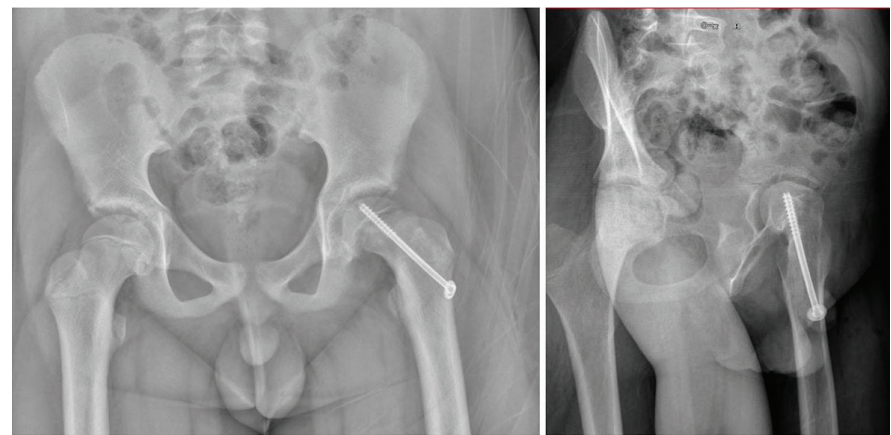

Figure 1. On the AP and lateral radiographs of our 10-year-old patient who applied to our emergency department with hip and thigh pain, the femoral head epiphysis is seen to have slid posteriorly and inferiorly AP: Anterior-posterior

Table 1. Age, gender, side, degree of shifting, and body mass index values of the patients before surgery

\begin{tabular}{|l|l|l|l|l|}
\hline Patient & Age & Gender & Slip angle (degrees) & BMI \\
\hline 1 & 10 & M & 70 & 26.1 \\
\hline 2 & 7 & M & $35(\mathrm{R})$ and 40 (L) & 29.7 \\
\hline 3 & 12 & M & 62 & 25.9 \\
\hline 4 & 10 & M & 26 & 26.5 \\
\hline 5 & 11 & M & 35 & 26.8 \\
\hline 6 & 12 & M & 40 & 28.2 \\
\hline 7 & 15 & M & 32 & 25.5 \\
\hline 8 & 12 & M & 42 & 27.1 \\
\hline 9 & 13 & M & 39 & 29.2 \\
\hline 10 & 14 & M & 51 & 26.3 \\
\hline 11 & 13 & M & 44 & 24.4 \\
\hline 12 & 13 & M & 36 & 26.2 \\
\hline \multicolumn{7}{|l|}{ Right, L: Left, M: Male, BMI: Body mass index } \\
\hline
\end{tabular}

screw will be applied. A $6.5 \mathrm{~mm}$ titanium spongious cannulated screw (TST, Istanbul, Turkey) was applied percutaneously under fluoroscopy control. The K-wire guided from the anterior of the basis of the femoral neck sent extracapsular toward the posteromedial, centralizing the femoral neck (Figure 2). Reduction and screw length was controlled by scopy. The opposite hips were also evaluated with movable scopy images, and no unstable epiphysis was observed except for the bilateral patient. Screw application to the opposite hip was performed only in one patient with a diagnosis of bilateral SCFE. The patients were mobilized with double crutches on the postoperative first day without loading the operative side. The patients were mobilized with a partial load from the sixth postoperative week. In the only patient with bilateral sliding, only in-bed movements were allowed for 6 weeks. All of the patients were discharged on the second postoperative day. 


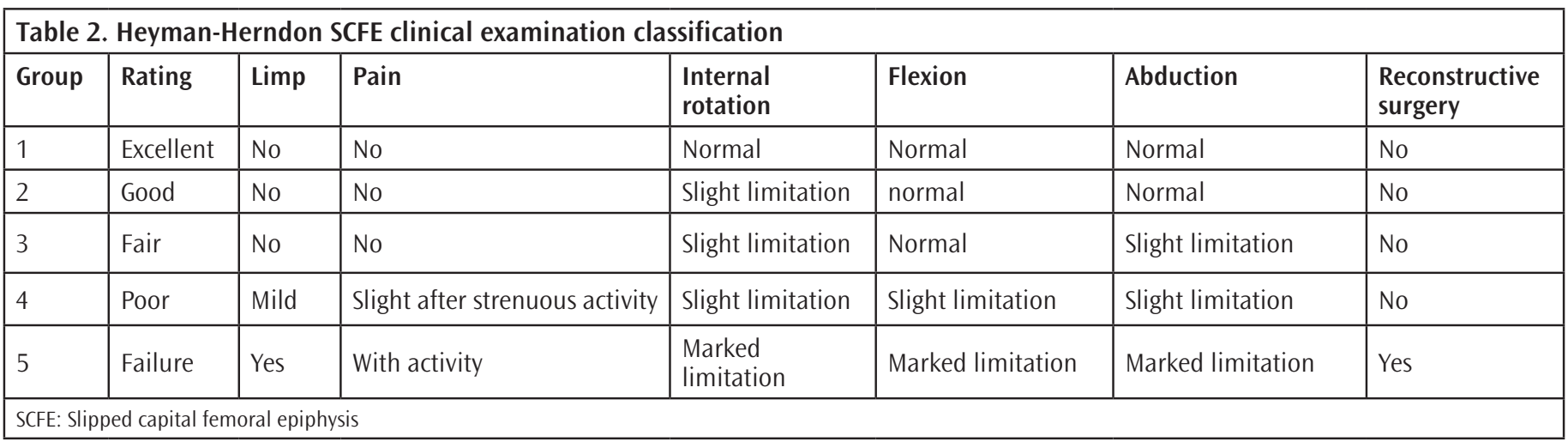
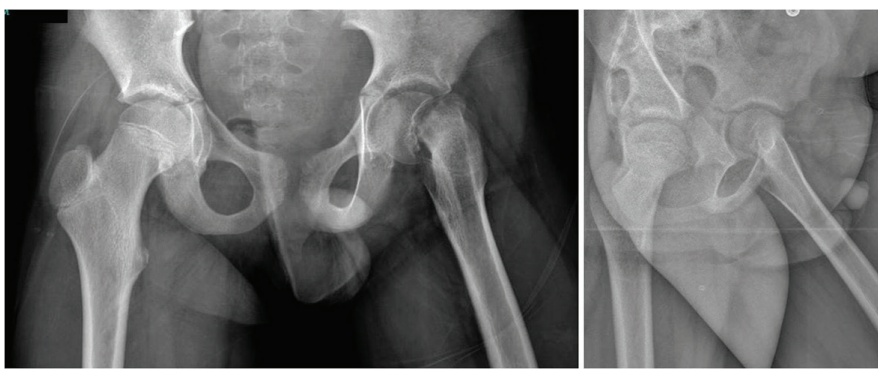

Figure 2. Our patient underwent osteosynthesis with a cannulated screw under emergency conditions

\section{Statistical Analysis}

The statistical analyses were performed using SPSS, version 22 (IBM SPSS Statistics for Windows, Armonk, NY; IBM Corp., Released 2013). No sample size estimations were performed because all patients in our hospital database who met the inclusion criteria were analyzed. Therefore, the statistical significance level was set to $p<0.05$.

\section{RESULTS}

Thirteen hips of 12 patients were evaluated clinically and radiologically. The age of the patients ranged from 7 to 15 years, and the mean age of patients who underwent surgery was 11.8 years. The average length of follow-up was 19 months (range 14-29 months). The average body mass index (BMI) was 26.8 (range 24.4-29.7), and 11 patients were overweight (91.7\%) (Table 1). With regard to ambulation, 7 patients had stable SCFE (58.3\%), and 5 had unstable SCFE (41.6\%). With respect to symptoms, there were 9 patients with acute SCFE (75\%), 2 patients with chronic SCFE (16.7\%), and 1 with acute episodes in the chronic phase (8.3\%). According to the Southwick classification, the average sliding degrees of the patients were 43.2 (range 26-70). In order to investigate the severity of displacement, we measured one hip with mild displacement, 9 hips with moderate displacement, and two hips with severe displacement. The postoperative range of motion was normal in all patients. Shortness and limping were not observed in any case. Subchondral cyst, osteophytic formation, and subchondral sclerosis were not observed in comparative radiographs of the patients. No degenerative changes were detected in any of our patients according to Boyer's criteria.

\section{DISCUSSION}

There are a limited number of studies on SCFE in our country. Our study retrospectively discussed the results of our patients diagnosed with acute and chronic SCFE and operated with a percutaneous single cannulated screw application. Despite the low number of patients, we found that our mid-term results correlated with the literature after single cannulated screw fixation.

SCFE femoral head is a condition in which the pineal plate changes inferiorly and posteriorly compared to its length. As a result, flexion, abduction, and internal rotation movements in the hip are restricted, and when the hip is intended to be flexed, it is directed toward external rotation (7).

SCFE is a disease most common in the 10-16 age range. The mean age of our patients was 11.8 (7-13). While the male/female ratio was $1.4 / 1$ in the literature, our entire patient group was males (4). Bilateral involvement in SCFE is around $20-25 \%(11,12)$. In our patient group, only one patient had bilateral SCFE, and its ratio to the patient group was $8.3 \%$.

Although the SCFE etiology is not fully known, environmental and genetic causes are emphasized. Endocrine causes such as hypogonadism, hypothyroidism, hypopituitarism, mechanical factors such as obesity and trauma, inflammatory diseases, and chronic kidney failure can be included in the etiology of the disease $(2,5)$. Especially in cases under 10 and over 16, endocrine causes must be investigated. In our patient group, the mean BMI was 26.8 (24.4-29.7) and was above average compared with the age, except for one patient. One of our patients who was evaluated as chronic SCFE was 7 years old with a BMI of 29.7. This patient 
was diagnosed with hypogonadism as a result of a pediatric endocrinology consultation.

The options for SCFE surgical treatment include in situ nailing for mild shifts, bone nails for moderate to severe shifts, and a combination of epiphysiodes and osteotomy or nailing and osteotomy according to the severity and level of the shift $(3,7,13)$. In recent years, the popular surgical method is single screw fixation $(7,8,14,15)$. However, Southwick osteotomy is recommended as a technically challenging but safe procedure, especially in treating chronic, stable, and moderate SCFE. It is stated that it corrects the deformity in the hip and provides a functional hip (16). However, we preferred the fixation method with one screw in three cases that we considered chronic. Some researchers suggest in situ nailings in moderate shifts, whereas others suggest epiphysiodes with bone nails (17-20). The increase in the number and size of implants used in surgical treatment also increases the complication rate. Accordingly, there is an increase in complications such as femoral head avascular necrosis, chondrolysis, penetration of the nail into the joint, and infection (7,21-23). Our shortest follow-up period was 14 months, and chondrolysis and avascular necrosis, which were shown to develop especially in the first year, were not observed in our follow-ups.

The prophylactic nailing of the opposite hip is still controversial in patients with unilateral involvement. Greenough et al. (24) observed that the complication rate increased in their series; therefore, they did not recommend prophylactic nailing. On the other hand, some authors suggest that the opposite hip should be preserved in patients who develop SCFE due to the high probability of bilateral disease $(25,26)$. We did not perform preventive surgery on any of our patients, and no slipped epiphysis was observed in the opposite hip of any of our patients.

For fixation in its location, it is necessary to provide a good AP and lateral vision with the help of a scopy on the traction table. In order to detect femoral head epiphysis in increasing slip degrees, the entry point of the nail is displaced toward the anterior cortex of the femoral neck (14). For all the patients in our study group, full AP and lateral images were taken on the traction table accompanied by scopy on the traction table, and nailing was performed with anterolateral entry. It has been reported in various studies that reduction maneuver causes poor results and that the risk of chondrolysis and avascular necrosis increases $(15,27)$. Six of our patients underwent mild reduction maneuvers, and none of the complications stated were observed in the follow-up of these patients.
A study conducted showed that the complication rate increased parallel with the increasing sliding degrees (15). The average sliding rate in our cases was 42.8. Therefore, we consider that not too high sliding degrees in our cases are another reason for no complications. Our follow-ups observed that hip flexion, internal rotation, and abduction, which were restricted preoperatively, improved, and excellent results were obtained in all of our patients.

\section{Study Limitations}

Our study has some limitations. The first limitation is that the same physician performed the radiological evaluation. Second, we did not have a large patient series and reported only midterm results.

\section{CONCLUSION}

We suggest that in SCFE cases requiring urgent surgery, the mild reduction can be considered, and subsequent osteosynthesis with a single screw is a sufficient treatment.

\section{Ethics}

Ethics Committee Approval: The study was conducted following the ethical standards stated in the "Declaration of Helsinki" and was approved by the Local Ethics Committee of Fatih Sultan Mehmet Training and Research Hospital (number: 17073117050.06).

Informed Consent: Informed consent was obtained from all patients.

Peer-review: Externally and internally peer-reviewed.

\section{Authorship Contributions}

Surgical and Medical Practices: T.E., A.T.P., Concept: T.E., Design: A.T.P., Data Collection or Processing: A.T.P., Analysis or Interpretation: T.E., Literature Search: A.T.P., Writing: T.E.

Conflict of Interest: No conflict of interest was declared by the authors.

Financial Disclosure: The authors declared that this study received no financial support.

\section{REFERENCES}

1. Lehmann CL, Arons RR, Loder RT, Vitale MG. The epidemiology of slipped capital femoral epiphysis: an update. J Pediatr Orthop 2006;26:286-90.

2. Georgiadis AG, Zaltz I. Slipped capital femoral epiphysis: How to evaluate with a review and update of treatment. Pediatr Clin North Am 2014;61:1119-35.

3. Naseem H, Chatterji S, Tsang K, Hakimi M, Chytas A, Alshryda S. Treatment of stable slipped capital femoral epiphysis: Systematic 
review and exploratory patient level analysis. J Orthop Traumatol 2017;18:379-94.

4. Loder RT. The demographics of slipped capital femoral epiphysis. An international multicenter study. Clin Orthop Relat Res 1996;8-27.

5. Gholve PA, Cameron DB, Millis MB. Slipped capital femoral epiphysis update. Curr Opin Pediatr 2009;21:39-45.

6. Hägglund G, Hannson LI, Sandström S. Slipped capital femoral epiphysis in southern Sweden. Long-term results after nailing/pinning. Clin Orthop Relat Res 1987;190-200.

7. Bittersohl B, Hosalkar HS, Zilkens C, Krauspe R. Current concepts in management of slipped capital femoral epiphysis. Hip Int 2015;25:10414.

8. Boyer DW, Mickelson MR, Ponseti IV. Slipped capital femoral epiphysis. Long-term follow-up study of one hundred and twenty-one patients. J Bone Joint Surg Am 1981;63:85-95.

9. Southwick WO. Osteotomy through the lesser trochanter for slipped capital femoral epiphysis. J Bone Joint Surg Am 1967;49:807-35.

10. Zahrawi FB, Stephens TL, Spencer GE Jr, Clough JM. Comparative study of pinning in situ and open epiphysiodesis in 105 patients with slipped capital femoral epiphyses. Clin Orthop Relat Res 1983;160-8.

11. Loder RT, Starnes T, Dikos G. Atypical and typical (idiopathic) slipped capital femoral epiphysis. Reconfirmation of the age-weight test and description of the height and age-height tests. J Bone Joint Surg Am 2006;88:1574-81.

12. Burrow SR, Alman B, Wright JG. Short stature as a screening test for endocrinopathy in slipped capital femoral epiphysis. J Bone Joint Surg Br 2001;83:263-8.

13. Slongo T, Kakaty D, Krause F, Ziebarth K. Treatment of slipped capital femoral epiphysis with a modified Dunn procedure. J Bone Joint Surg Am 2010;92:2898-908.

14. Aronson DD, Carlson WE. Slipped capital femoral epiphysis. A prospective study of fixation with a single screw. J Bone Joint Surg Am 1992;74:8109 .

15. Boero S, Brunenghi GM, Carbone M, Stella G, Calevo MG. Pinning in slipped capital femoral epiphysis: Long-term follow-up study. J Pediatr Orthop B 2003;12:372-9.
16. Coppola C, Sadile F, Lotito FM, Cigala F, Shanmugam C, Maffulli N. Stabil femur başi epifiz kaymasinda Southwick osteotomisi: Uzun dönem sonuçlar [Southwick osteotomy in stable slipped capital femoral epiphysis: a long-term outcome study]. Acta Orthop Traumatol Turc 2008;42:358-64.

17. Cullu E, Damgaci K, Savk SO. Femur bași epifiz kaymasinda olduğu pozisyonda tek vida ile tespit [In situ pinning on slipped femoral capital epiphysis with a single cannulated screw]. Ulus Travma Acil Cerrahi Derg 2005; 11:212-7.

18. Sibiński M, Synder M, Borowski A, Grzegorzewski A. Przebudowa blizszego końca kości udowej po szyjkowo-glowowej transfiksji in situ w młodzieńczym złuszczeniu [Remodeling after in situ pinning for slipped capital femoral epiphysis]. Chir Narzadow Ruchu Ortop Pol 2004;69:321-4.

19. Adamczyk MJ, Weiner DS, Hawk D. A 50-year experience with bone graft epiphysiodesis in the treatment of slipped capital femoral epiphysis. J Pediatr Orthop 2003;23:578-83.

20. Schmidt TL, Cimino WG, Seidel FG. Allograft epiphysiodesis for slipped capital femoral epiphysis. Clin Orthop Relat Res 1996;61-76.

21. Seller K, Raab P, Wild A, Krauspe R. Risk-benefit analysis of prophylactic pinning in slipped capital femoral epiphysis. J Pediatr Orthop B 2001;10:192-6.

22. Loder RT, Richards BS, Shapiro PS, Reznick LR, Aronson DD. Acute slipped capital femoral epiphysis: the importance of physeal stability. J Bone Joint Surg Am 1993;75:1134-40.

23. Tudisco C, Caterini R, Farsetti P, Potenza V. Chondrolysis of the hip complicating slipped capital femoral epiphysis: long-term follow-up of nine patients. J Pediatr Orthop B 1999;8:107-11.

24. Greenough CG, Bromage JD, Jackson AM. Pinning of the slipped upper femoral epiphysis--a trouble-free procedure? J Pediatr Orthop 1985;5:657-60

25. Hägglund G. The contralateral hip in slipped capital femoral epiphysis. J Pediatr Orthop B 1996;5:158-61.

26. Loder RT, Hensinger RN. Slipped capital femoral epiphysis associated with renal failure osteodystrophy. J Pediatr Orthop 1997;17:205-11.

27. Stevens DB, Short BA, Burch JM. In situ fixation of the slipped capital femoral epiphysis with a single screw. J Pediatr Orthop B 1996;5:85-9. 